\title{
Natural history of
}

\section{rheumatoid cervical luxations}

\author{
P. H. SMITH \\ University of Manchester Department of Rheumatism, Manchester Royal Infirmary,
} R. T. BENN

Arthritis and Rheumatism Council Field Unit, Clinical Sciences Building, York Place, Manchester 13, AND

J. SHARP

Rheumatism Department, University Hospital of South Manchester, Withington Hospital, Manchester 20

Luxation of the cervical spine, if looked for, is commonly observed at some stage during the longterm care of patients with rheumatoid arthritis. At the atlanto-axial level up to a quarter of patients admitted to hospital with rheumatoid arthritis can be expected to have luxations and about half will have subaxial luxations at two or more levels (Sharp and Purser, 1961 ; Conlon, Isdale, and Rose, 1966; Sharp, 1964).

Pain and stiffness in the neck may be present but are frequently absent and often the luxations cause no symptoms or disability. Occasionally the presenting symptoms are transient blackouts, tetraplegia, sudden death, or other neurological complications resulting from damage to the cervical cord or interference with the flow of the vertebral arteries (Ball and Sharp, 1971).

In this paper we report the results of a study of the natural history of cervical luxation in patients with rheumatoid arthritis, with particular reference to the development of dangerous neurological complications.

\section{Patients studied}

Between the years 1955 and 1964 all patients with rheumatoid arthritis who were admitted to the beds of the

Table I A Age, sex, and incidence of luxations in 962 hospital in-patients with rheumatoid arthritis

\begin{tabular}{|c|c|c|c|c|c|}
\hline \multirow[t]{2}{*}{ Sex } & & \multicolumn{2}{|l|}{ Male } & \multicolumn{2}{|l|}{ Female } \\
\hline & & Luxations & None & Luxations & None \\
\hline $\begin{array}{l}\text { Age } \\
\text { (yrs) }\end{array}$ & $\begin{array}{r}0-19 \\
20-29 \\
30-39 \\
40-49 \\
50-59 \\
60-69 \\
70-79\end{array}$ & $\begin{array}{r}1 \\
4 \\
6 \\
16 \\
18\end{array}$ & $\begin{array}{r}3 \\
13 \\
24 \\
78 \\
106 \\
94 \\
11\end{array}$ & $\begin{array}{r}1 \\
2 \\
9 \\
23 \\
41 \\
24 \\
5\end{array}$ & $\begin{array}{r}16 \\
12 \\
59 \\
119 \\
170 \\
94 \\
13\end{array}$ \\
\hline Total & & 45 & 329 & 105 & 483 \\
\hline
\end{tabular}

Accepted for publication April 5, 1972
Rheumatism Department of the Manchester Royal Infirmary had lateral radiographs of the cervical spine in extension and flexion, and these totalled 751 ( 442 females and 309 males). Similar films were taken of all the 211 patients (146 females and 65 males) with rheumatoid arthritis who were admitted to the Devonshire Royal Hospital from 1961 to 1964 under the care of Dr. Sharp.

The films of these 962 patients were examined by one observer for the presence of cervical luxations, using standards described later in the section on radiological criteria.

Of the original 962 patients, 150 were found to have cervical luxations at one or more levels. Tables IA and IB show the relationship of sex, age, and duration of rheumatoid arthritis in the 150 patients with luxations and the 812 patients without such lesions.

Twenty of these 150 patients had evidence of spinal cord or brainstem involvement at the time of admission and these will be discussed elsewhere. In this paper we are reporting on the progress of the remaining 130 patients in whom there was no evidence of neurological complications at the time of admission to hospital.

Each of the 130 patients was assessed retrospectively with the help of the hospital notes for a history of neck pain and instability symptoms; their functional class (according to the criteria of Steinbrocker, Traeger, and Batterman, 1949) and the results of their sheep cell agglutination and latex-fixation tests were noted, as were details of steroid therapy.

Table I B Duration of rheumatoid arthritis, sex, and incidence of luxations in 962 hospital in-patients

\begin{tabular}{|c|c|c|c|c|c|}
\hline \multirow{2}{*}{\multicolumn{2}{|c|}{ Sex }} & \multicolumn{2}{|l|}{ Male } & \multicolumn{2}{|l|}{ Female } \\
\hline & & Luxations & None & Luxations & None \\
\hline $\begin{array}{l}\text { Duration } \\
\text { (yrs) }\end{array}$ & $\begin{array}{l}0-4 \\
5-9 \\
10-14 \\
15-19 \\
20-24 \\
25-29 \\
30\end{array}$ & $\begin{array}{r}7 \\
14 \\
12 \\
7 \\
4 \\
1\end{array}$ & $\begin{array}{r}197 \\
54 \\
31 \\
19 \\
14 \\
8 \\
6\end{array}$ & $\begin{array}{r}16 \\
23 \\
24 \\
24 \\
9 \\
4 \\
5\end{array}$ & $\begin{array}{r}310 \\
34 \\
71 \\
33 \\
23 \\
7 \\
5\end{array}$ \\
\hline Total & & 45 & 329 & 105 & 483 \\
\hline
\end{tabular}


Between August, 1969, and December, 1970, all of the 130 patients were traced; this was done with the help of general practitioners, local Medical Executive Committees, and the National Health Service Central Register. Before August, 1969, 46 of these patients died; the 84 survivors ( 64 females and 20 males) were reviewed, either in the hospital out-patients department or in the patient's own home, and all but three of these patients were examined by one observer. At each review attention was given to any history of neck pain or instability symptoms and enquiry was made about neurological symptoms, the wearing of collars, neck operations, and steroid therapy. A full neurological examination was then done and clinical abnormalities in the cervical and dorso-lumbar spines were noted. Lastly, an assessment of their functional class was made, blood for sheep cell agglutination and latex-fixation tests, and radiographs of the hands and of the cervical spine in extension and flexion were taken.

During the course of the study a further six patients died; in each case a follow-up examination had been done. The total number of deaths was thus 52 and the certified causes of death were obtained in 47 of these. Approximately half of this information was acquired from the general practitioners of the deceased and the remainder was supplied by the National Health Service Central Register.

Finally, two observers independently graded the initial and follow-up radiographs of the neck and hands (see radiological criteria) and those in whom there was a disparity were re-read jointly.

\section{Radiological criteria}

At the atlanto-axial level, forward luxation was considered to be present if a gap of $3.5 \mathrm{~mm}$. or more was observed between the atlas and odontoid process on the lateral radiograph taken of the neck in flexion; the measurement was recorded from the middle of the posterior surface of

$$
\text { AT CI AND C } 2
$$

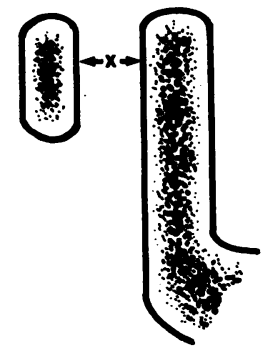

LUXATION $\times \mathrm{mm}$

FIG. 1. Measurement of forward luxation of C.1 on C.2 the anterior arch of the atlas to the anterior surface of the odontoid (Fig. 1). Table II shows the method of grading forward luxations at the atlanto-axial level together with the numbers in these categories among the original 130 patients.

Downward luxation of the atlas on the axis, as illustrated in Fig. 2, was found in nine of the original 130 patients. The presence of this type of luxation was assessed subjectively as we were unable to devise a satisfactory method of either measuring or grading such lesions.

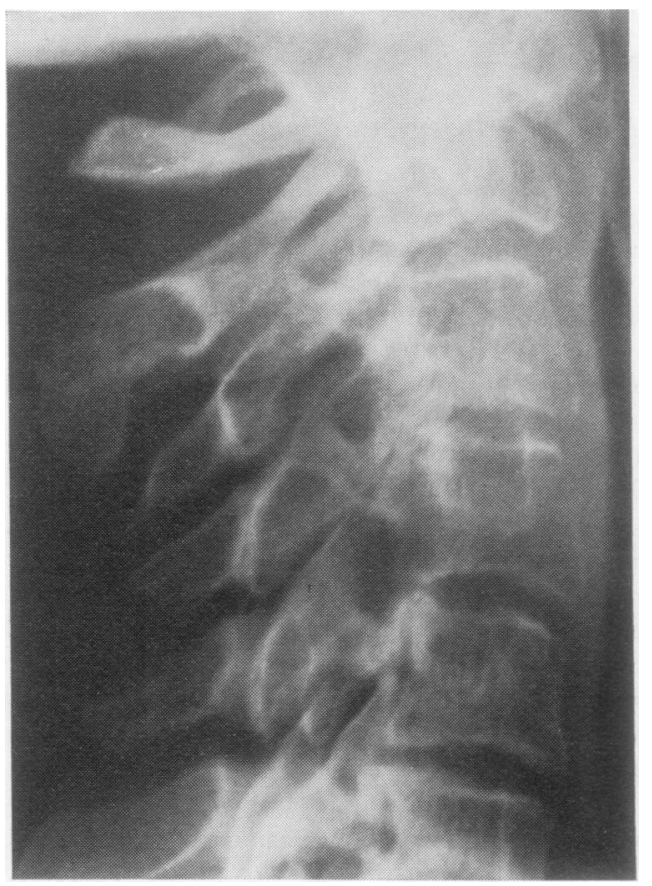

FIG. 2 Downward luxation of C.1 on C.2

Below the level of the atlas, forward or backward uxation was expressed as a percentage of the anteroposterior diameter of the upper plate of the lower vertebra, and a displacement of 15 per cent was regarded as a significant displacement (Fig. 3). Table II shows the method of grading these luxations and also the numbers in these categories among the original 130 patients. Fig. 4 shows examples of the various grades of luxation both at C.1/2 and below C.1. Table III demonstrates the numbers of luxations among the original 130 patients and the 84 survivors.

Radiographs of the hands had been taken in all the 130 patients at the time of admission to hospital; these films

Table II Grading and distribution of forward and backward luxations in 130 patients at C.1/2 and below C.1

\begin{tabular}{|c|c|c|c|c|}
\hline \multirow[t]{2}{*}{ Grade } & At C.1/2 & No. of cases & Below C.1 & No. of cases \\
\hline & Forward subluxation ( $\mathrm{mm})$. & & Forward and backward subluxation $(\%)$ & \\
\hline $\begin{array}{l}2 \\
3 \\
4\end{array}$ & $\begin{array}{l}3 \cdot 5-5.0 \\
5 \cdot 5-7 \cdot 5 \\
8 \cdot 0 \text { and over }\end{array}$ & $\begin{array}{l}48 \\
32 \\
11\end{array}$ & $\begin{array}{l}15-25 \\
26-32 \\
33 \text { and over }\end{array}$ & $\begin{array}{r}66 \\
18 \\
1\end{array}$ \\
\hline
\end{tabular}


were read together with those taken on the 84 survivors for anatomical stage of rheumatoid disease, according to the criteria of Steinbrocker and others (1949).

\section{BELOW C I}

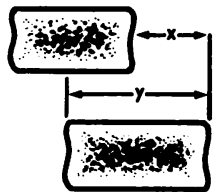

LUXATION $\frac{x}{y}^{100 \text { per cent }}$

FIG. 3 Measurement of luxations below C.1

Table III Numbers of luxations in the original 130 patients and survivors

\begin{tabular}{llll}
\hline $\begin{array}{l}\text { Number of } \\
\text { luxations }\end{array}$ & $\begin{array}{l}\text { Original } \\
\text { 130 patients }\end{array}$ & 84 survivors \\
\cline { 1 - 1 } 2 & 92 & 58 \\
3 & 22 & 15 \\
4 & 15 & 11 \\
\hline
\end{tabular}

\section{Results}

The original 130 patients comprised 89 females and 41 males and at the time of their inclusion in this series their ages ranged from 17 to 73 years; the average being $49 \cdot 1$ years in females and $52 \cdot 4$ years in males.

In the patients with cervical luxation, the average duration of rheumatoid arthritis was 12.5 years; males had a shorter average disease duration of 8.9 years, as compared with 13.5 years in females (range 4 months to 41 years).

At the initial examination 92 patients ( 70 per cent) were severely disabled, being placed in functional class 3 or 4 , and amongst the survivors at follow-up the proportion with this degree of incapacity was almost identical at 71 per cent ( 60 out of 84 ). Female patients were found to be more severely incapacitated than males at both the initial and follow-up examinations.

Table IV (overleaf) shows the relationship between the average duration of rheumatoid arthritis and the severity of luxations, but it omits the average disease duration for downward luxation, which was 18.7 years. From this Table it is evident that below C. 1 the severity of luxations was closely related to rheumatoid disease duration; at C. $1 / 2$ forward luxations did not show this correlation, whereas downward luxations were associated with long disease
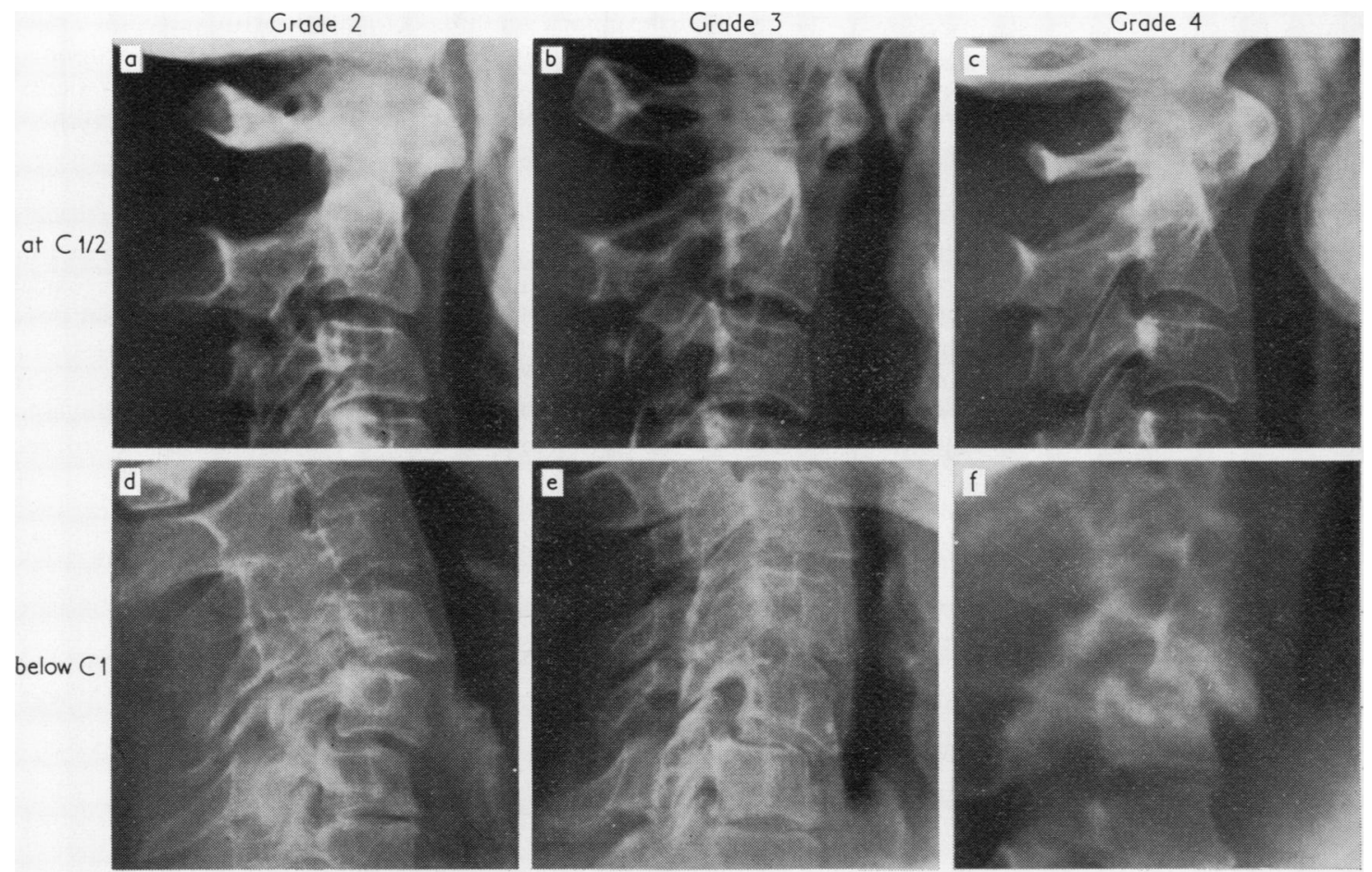

FIG. 4 Illustrations of grade of cervical luxation in the cervical spine (flexion views) 
duration. These observations are in accordance with the finding that downward luxations at C.1/2 and the more severe luxations below C.1 occurred in the older age groups; thus, out of the total of nineteen patients with downward luxation, only three were less than 60 years of age when this was diagnosed. Forward luxations at C.1/2 did not show this age relationship.

Table IV Relation between duration of rheumatoid arthritis and severity of luxations at C.1/2 and below C.1

\begin{tabular}{|c|c|c|}
\hline \multirow[t]{2}{*}{ Grade } & \multicolumn{2}{|c|}{ Duration of $R A(y r s)$} \\
\hline & Luxation C.1/2 & Luxation below $C .1$ \\
\hline $\begin{array}{l}2 \\
3 \\
4\end{array}$ & $\begin{array}{l}11 \cdot 2 \\
11 \cdot 8 \\
12 \cdot 4\end{array}$ & $\begin{array}{l}12 \cdot 8 \\
18 \cdot 0 \\
27 \cdot 6\end{array}$ \\
\hline
\end{tabular}

The 84 survivors were followed up for between 5 and 14 years (average $7 \cdot 8$ years) and their radiological progress is shown in Table V.

Table V $a$ summarizes the progress of luxations of the atlas on the axis. The initial numbers in the various grades are shown in the vertical axis. There were thirty with Grade 2, nineteen with Grade 3, and six with Grade 4 luxations. The numbers in the various grades at the follow-up examination are shown on the horizontal axis. The numbers intersected by the diagonal dotted line represent the 28 patients whose luxations remained unaltered. The numbers above and to the left of the diagonal indicate the eight patients whose luxations improved or recovered completely, whilst the numbers below and to the right of the diagonal denote the nineteen whose luxations increased in severity. Of the five patients with Grade 4 luxations both initially and finally, there was only one in whom there was a measurable increase in the degree of luxation, from 10 to $12 \mathrm{~mm}$. It is of interest that, in five patients who initially had luxations, including one in Grade 4, the displacements were no longer demonstrable at follow-up (Fig. 5, opposite).

Table $\mathrm{V} a$ omits seven patients with forward luxation initially who developed downward luxation, and four patients in whom there was downward luxation both initially and finally.

Table $\mathrm{V} b$ summarizes the progress of the 55 luxations below the atlas; of these 47 were forward and eight were backward. The numbers intersected by the diagonal dotted line represent the 23 luxations which remained unaltered, the numbers above and to the left of the diagonal denote the 23 which improved or were no longer demonstrable, whilst the numbers below and to the right of the diagonal indicate the nine luxations which increased. It should be noted that eighteen luxations were no longer demonstrable at follow-up, including two of Grade 3 severity. Forward and backward luxations seemed to progress in much the same manner.

At the outset 104 patients ( 83 per cent.) had Stage 3 or 4 anatomical changes in their hands, and amongst the survivors the proportion in Stage 3 or 4 was almost identical (86 per cent.).

\section{NEUROLOGICAL LESIONS}

Between the initial and follow-up examination three of the original 130 patients developed clinical evidence of cord involvement; cord compression was given as the cause of death in another patient who died without a follow-up examination. A further six patients developed features compatible with vertebral artery involvement. Vertebral angiograms were not done as the risks were not felt to be justified in these patients. Clinical details of these ten patients are given in Tables VIA and VIB.

\section{SUR VIVAL}

Life tables for the male and female patients in this series were constructed by standard actuarial methods, making the arbitrary assumption that their survival from birth to age $\mathbf{4 0}$ was the same as in the 1961 Life Tables for England and Wales (Registrar General, 1968). It was possible to compare the subsequent survival of the patients with that of the

Table V Radiological progress of luxations in 84 patients (a) at C.1/2 and (b) below C.1

at $\mathrm{C} 1 / 2$

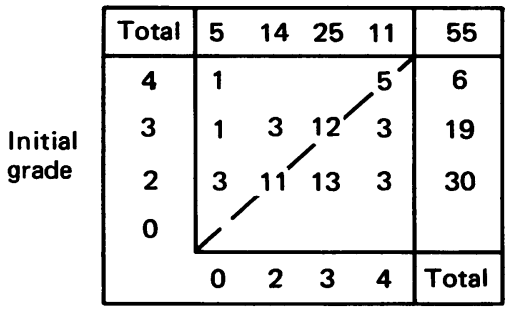

Final grade
Below C1

\begin{tabular}{|c|c|c|c|c|}
\hline Total & 1825 & 9 & 3 & 55 \\
\hline \multicolumn{5}{|l|}{4} \\
\hline 3 & 5 & $3^{\prime}$ & 1 & 11 \\
\hline 2 & 1620 & 6 & 2 & 44 \\
\hline & 0 & 3 & 4 & Total \\
\hline
\end{tabular}

Final grade 


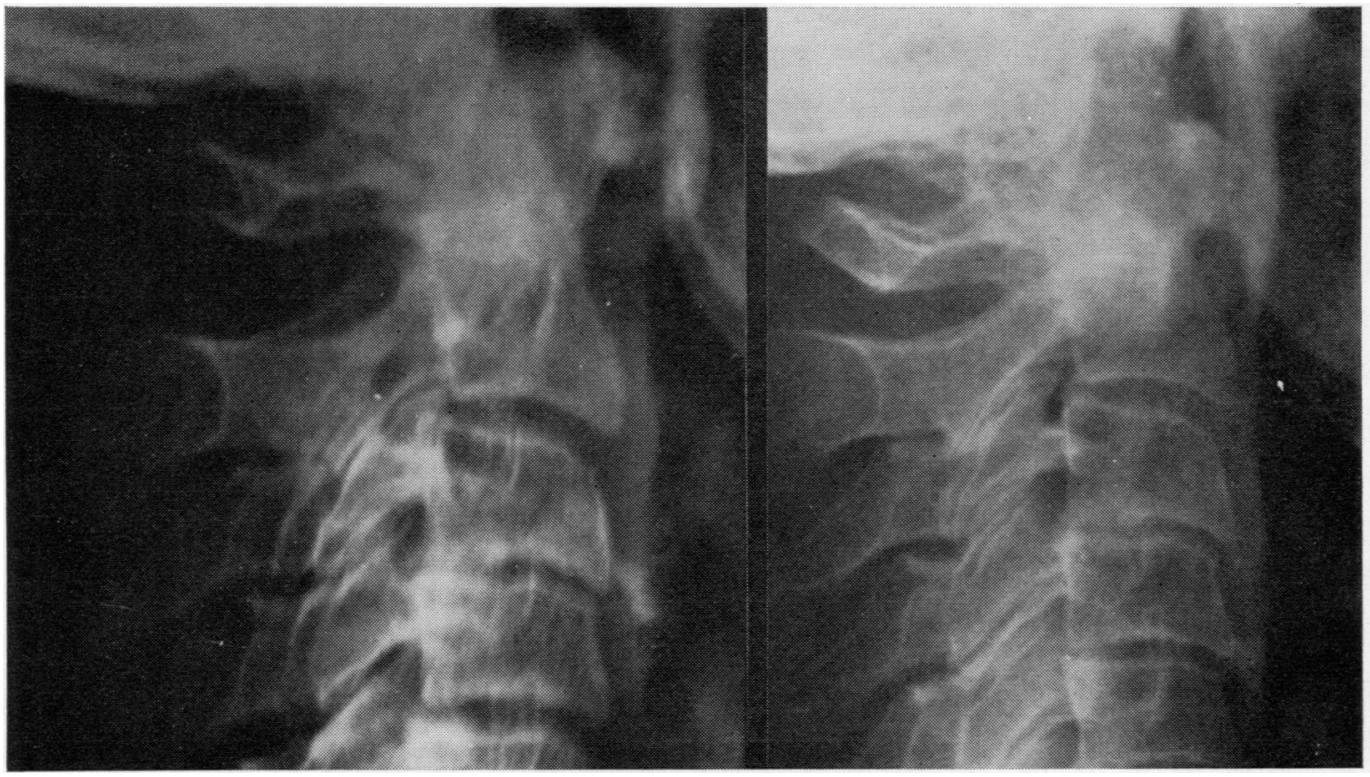

FIG. 5 Spontaneous recovery of Grade 3 forward luxation of C.1 on C.2 (flexion views)

Table VI A Details of 4 patients with cord involvement

\begin{tabular}{|c|c|c|c|c|c|c|c|c|c|c|c|c|}
\hline \multirow[t]{2}{*}{ Age } & \multirow[t]{2}{*}{$\operatorname{Sex}$} & \multicolumn{3}{|c|}{ Diagnosis of luxation } & \multirow[t]{2}{*}{ Steroids } & \multicolumn{3}{|c|}{ Cervical cord involvement } & \multirow{2}{*}{$\begin{array}{l}\text { Cervical } \\
\text { fusion } \\
\text { opera- } \\
\text { tion }\end{array}$} & \multicolumn{3}{|c|}{ Follow-up } \\
\hline & & Date & $\begin{array}{l}\text { Duration } \\
\text { of } R A \\
(y r s)\end{array}$ & $\begin{array}{l}\text { Cervical spine } \\
\text { radiograph }\end{array}$ & & Date & Signs & $\begin{array}{l}\text { Cervical } \\
\text { spine } \\
\text { radiograph }\end{array}$ & & Date & Alive & Certified causes of death \\
\hline$\overline{32}$ & $\bar{F}$ & $\overline{1958}$ & 17 & C.1/2 FL G4 & & 1964 & $\begin{array}{l}\text { Hyper-reflexia } \\
\text { Plantars } \mathbb{L} \mathbb{}\end{array}$ & C.1/2 FL G4 & $\sqrt{ }$ & 1970 & $\sqrt{ }$ & \\
\hline 67 & $\mathbf{F}$ & 1964 & 1 & C. $2 / 3$ FL G3 & $\sqrt{ }^{\prime}$ & 1966 & $\begin{array}{l}\text { Vibration } \downarrow \\
\text { L. leg } \\
\text { Light touch } \downarrow \\
\text { L. Vth Ist Div. } \\
\text { L. trunk } \\
\text { Plantars } 11\end{array}$ & C.2/3 FL G2 & & 1970 & $\sqrt{ }$ & \\
\hline 64 & $\mathbf{F}$ & 1964 & 1 & C.1/2 FL G3 & $\sqrt{ }$ & 1970 & $\begin{array}{l}\text { Hyper-reflexia } \\
\text { Plantars } \uparrow \uparrow\end{array}$ & C.1/2 FL G4 & $\sqrt{ }$ & 1970 & & $\begin{array}{l}\text { 1a Pneumonia } \\
\text { b Cord compression } \\
2 \text { Rheumatoid arthritis }\end{array}$ \\
\hline 53 & $\mathbf{F}$ & 1965 & 20 & $\begin{array}{l}\text { C. } 1 / 2\left\{\begin{array}{l}\text { DL X } \\
\text { FL G3 X } \\
\text { C.5/6 }\end{array} \text { FL G2 }\right.\end{array}$ & $\sqrt{ }$ & & & & & 1969 & & $\begin{array}{l}\text { 1a Pyelonephritis } \\
\text { b Tetraplegia } \\
2 \text { Rheumatoid arthritis }\end{array}$ \\
\hline
\end{tabular}

DL Downward luxation

FL Forward luxation

G Grade

2 Rheumatoid arthritis

national population. Similar tables were available derived from a 20-year follow-up of a series of patients with definite or classical rheumatoid arthritis (Reah, 1963; Reah, Benn, and Wood, 1971). Those whom Reah classed initially as being moderately or severely incapacitated (15 females and 27 males) were functionally comparable with the majority of the present series of patients. Figs $6 a$ and $6 b$ (overleaf) show comparisons of survival in females and males respectively. It appears that while lifeexpectancy in patients with moderate or severe rheumatoid arthritis is worse than that of the general population, cervical luxation per se does not influence life-expectancy. The systematic analysis of the effect of a given characteristic on survival has hitherto been neglected in rheumatology. The classic examples of life-table methods in clinical medicine were connected with cancers, but they can also be useful in studying chronic, less fatal conditions.

We have also followed-up twenty other rheumatoid patients who were not included in this series; these were patients with cord lesions due to cervical luxations and fifteen have since died. It is of interest that, although thirteen of these fifteen patients were 
Table VI B Details of 6 patients with ?vertebral artery involvement

\begin{tabular}{|c|c|c|c|c|c|c|c|c|c|c|}
\hline \multirow[t]{2}{*}{ Age } & \multirow[t]{2}{*}{$\operatorname{Sex}$} & \multicolumn{3}{|c|}{ Diagnosis of luxation } & \multirow[t]{2}{*}{ Steroids } & \multicolumn{3}{|c|}{ ? Vertebral artery involvement } & \multicolumn{2}{|c|}{ Follow-up } \\
\hline & & Date & $\begin{array}{l}\text { Cervical spine } \\
\text { radiograph }\end{array}$ & $\begin{array}{l}\text { Duration } \\
\text { of } R A \\
\text { (yrs) }\end{array}$ & & Date & Symptoms and signs & $\begin{array}{l}\text { Cervical spine } \\
\text { radiograph }\end{array}$ & Date & Alive \\
\hline 62 & $\mathbf{M}$ & 1962 & C.1/2 FL G2 & 21 & & 1969 & $\begin{array}{l}\text { Lightheaded episodes } \\
\text { Loss of consciousness }\end{array}$ & $\begin{array}{l}\text { C.1/2 DL X } \\
\text { C. } 2 / 3 \text { FL G2 }\end{array}$ & 1970 & $\sqrt{ }$ \\
\hline 52 & $\mathbf{M}$ & 1961 & $\begin{array}{l}\text { C.1/2 FL G2 } \\
\left.\begin{array}{l}\text { C.3/4 } \\
\text { C.4/5 }\end{array}\right\} \text { BL G2 }\end{array}$ & 6 & $\sqrt{ }$ & 1969 & $\begin{array}{l}\text { Hemianaesthesia } \\
\text { episodes B.P. 220/130 }\end{array}$ & $\begin{array}{l}\text { C. } 1 / 2 \text { FL G3 } \\
\left.\begin{array}{l}\text { C. } 3 / 4 \\
\text { C.4/5 }\end{array}\right\} \text { BL G2 }\end{array}$ & 1970 & $\sqrt{ }$ \\
\hline 35 & $\mathbf{F}$ & 1963 & C.1/2 FL G2 & 5 & $\sqrt{ }$ & 1969 & $\begin{array}{l}\text { Lightheaded episodes } \\
\text { Loss of consciousness }\end{array}$ & C.1/2 FL G2 & 1970 & $\sqrt{ }$ \\
\hline 48 & $\mathbf{F}$ & 1960 & C.1/2 FL G3 & 16 & & 1965 & $\begin{array}{l}\text { Tingling left arm and } \\
\text { upper chest-on turning } \\
\text { head }\end{array}$ & C.1/2 FL G3 & 1970 & $\sqrt{ }$ \\
\hline 55 & $\mathbf{F}$ & 1962 & $\begin{array}{l}\text { C. } 1 / 2 \text { DL X } \\
\text { C.4/5 FL G2 X } \\
\text { C.5/6 FL G3 }\end{array}$ & 27 & & 1968 & Drop attacks & $\begin{array}{l}\text { C.1/2 DL X } \\
\text { C.3/4 FL G2 } \\
\text { C.4/5 FL G2 } \\
\text { C.5/6 FL G3 }\end{array}$ & 1970 & $\sqrt{ }$ \\
\hline 53 & $\mathbf{F}$ & 1964 & C.1/2 FL G2 & 12 & $\sqrt{ }$ & 1967 & Lightheaded episodes & C.1/2 FL G3 & 1970 & $\sqrt{ }$ \\
\hline
\end{tabular}

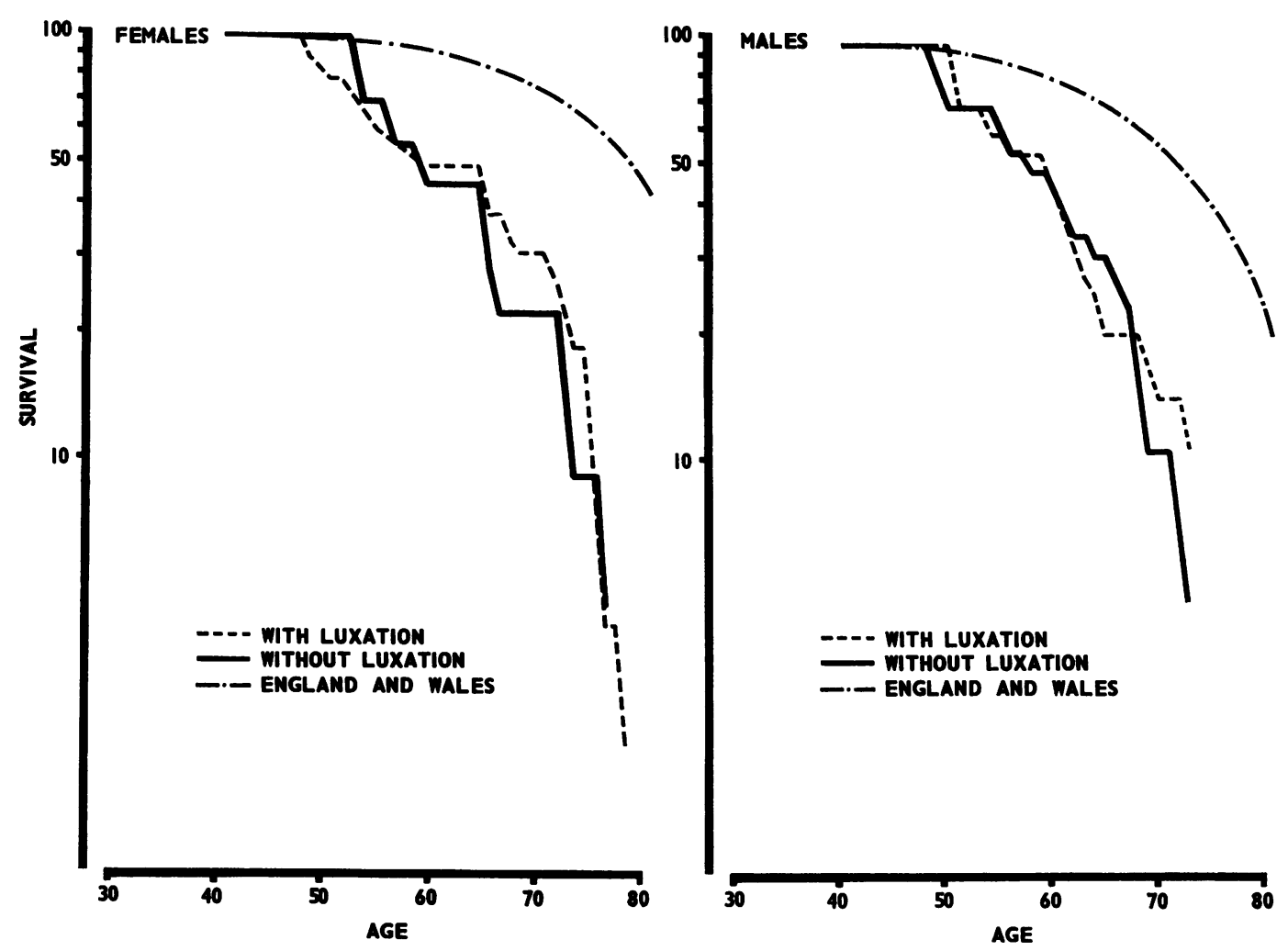


known to have had residual cord signs after treatment, only two of their death certificates mention cord lesions. This casts some doubt on the finding that the various certifiable causes of death in this series were proportionally the same as those in the general population of England and Wales.

The data were analysed to establish whether a positive sheep cell agglutination test, the wearing of collars or corticosteroid therapy affected the prognosis of luxations.

\section{SHEEP CELL AGGLUTINATION TEST}

This test was negative in only eleven of the 130 patients and seven of these survived to follow-up. Radiological deterioration, and cord or brainstem involvement did not occur in these patients, and of the four who died neither cervical luxation nor cord lesions was mentioned on the death certificates.

\section{COLLARS}

These were given to 45 of the 84 survivors:

Group $A(31)\left\{\begin{array}{l}9 \text { never wore their collars } \\ 22 \text { wore their collars intermittently }\end{array}\right.$
Group $B(14)\left\{\begin{array}{l}4 \text { wore their collars most days or most } \\ \text { nights } \\ 3 \text { wore their collars every day and most } \\ \text { nights } \\ 7 \text { wore their collars every day and night }\end{array}\right.$

Group A patients wore their collars too infrequently for them to have provided any possible benefit.
Table VII $a$ and VII $b$ show the radiological progress of luxations at C.1/2 in the fourteen Group B patients who wore collars regularly, and also in the remaining seventy patients who were either not provided with collars or who wore them ineffectively. Table VII $a$ omits one patient with a forward luxation which progressed to a downward luxation; Table VII $b$ excludes six patients with forward luxations which evolved into downward luxations and also four patients with downward luxations both initially and finally. Assuming that the final development of a downward luxation signifies a deterioration, then, in the group who wore collars effectively, 43 per cent $(3$ out of 7) deteriorated, as compared with 39 per cent (23 out of 59) of the remainder.

Tables VIII $a$ and VIII $b$ demonstrate the radiological progress of the fifteen luxations below C. 1 in the fourteen patients who wore collars regularly and also of the forty luxations in the remaining forty patients. Thirteen per cent ( 2 out of 15$)$ of luxations in the former group deteriorated, as compared with 18 per cent ( 7 out of 40 ) in the latter. It may be concluded that collars of the type prescribed were ineffective.

\section{STEROIDS}

Corticosteroids had been taken by 62 of the 84 patients who were re-examined; 85 per cent of these had been treated with steroids for between 6 and 15 years. A comparison of the functional capabilities of
Table VII Radiological progress of luxations at C.1/2 (a) 14 patients 'with collars'

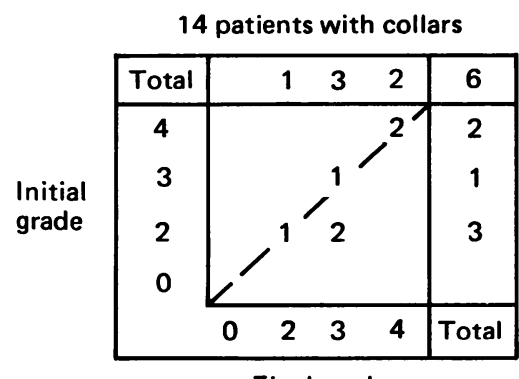

Final grade

Table VIII Radiological progression of luxations below C.1

(a) 14 patients 'with collars'

14 patients with collars

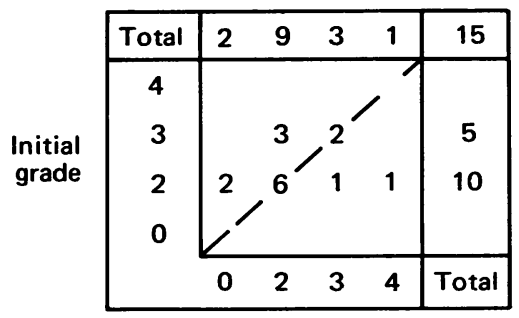

Final grade (b) 70 patients 'without collars'

70 patients without collars

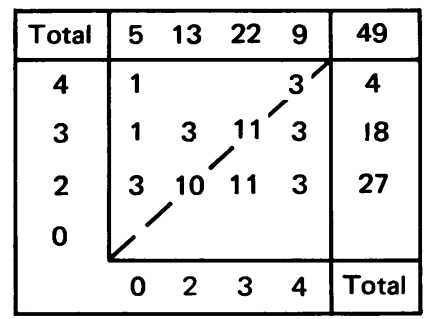

Final grade

(b) 70 patients 'without collars'

70 patients without collars

\begin{tabular}{|c|cccc|c|}
\hline Total & 16 & 16 & 6 & 2 & 40 \\
\hline 4 & & & & & \\
3 & 2 & 2 & 1 & 1 & 6 \\
2 & 14 & 14 & 5 & 1 & 34 \\
0 & & & & & \\
\hline & 0 & 2 & 3 & 4 & Total \\
\hline
\end{tabular}

Final grade 
the steroid and non-steroid treated patients showed no significant differences and the age and disease duration of these two groups were similar except that there were slightly more young patients and patients with rheumatoid disease of short duration amongst those taking steroids.

The radiological progress of the steroid as compared with the non-steroid treated group is shown in Tables IX $a$ and IX $b, \mathrm{X} a$ and $\mathrm{X} b$.

Table IX $a$ omits one patient in whom there was downward luxation both initially and finally. Table IX $b$ excludes seven patients with forward luxation who finally developed downward luxation and three patients in whom there was downward luxation both initially and finally.

These Tables suggest that the incidence of both atlanto-axial and lower luxations was approximately equal in both the steroid and non-steroid treated groups. It also appears that forward luxations at C.1/2 progressed poorly in patients taking steroids when compared with similar lesions found in those not receiving this drug. The difference in the progression of subaxial luxations between these two groups was not so marked, but there seemed to be less deterioration among those taking steroids.

\section{Discussion}

Damage to the spinal cord or vertebral artery involvement are the main hazards of rheumatoid cervical

Table IX Radiological progress of luxations at C.1/2 (a) non-steroid treated patients

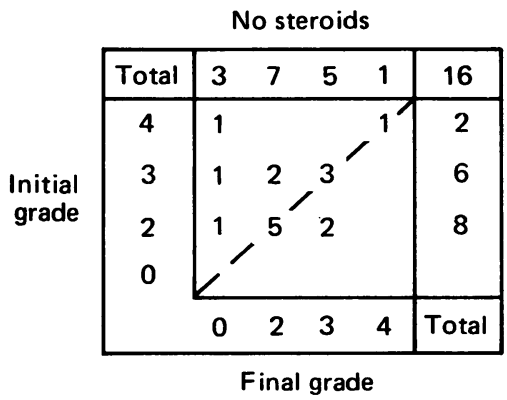

Table X Radiological progress of luxations below C.1 (a) non-steroid treated patients

No steroids

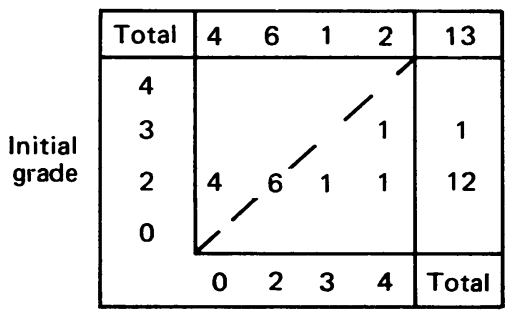

Final grade luxations. During a follow-up period averaging $7 \cdot 8$ years (range 5 to 14), three out of 130 patients with rheumatoid cervical luxation developed clinical signs of damage to the cervical cord and a further six complained of symptoms compatible with vertebral artery involvement.

46 patients died without follow-up examination and, of the 41 available death certificates, only one suggests that death was due to cord involvement. Death resulting from cord or brainstem involvement could easily be misdiagnosed as a myocardial infarction or a cerebro-vascular accident but the actual number of deaths from these disorders did not exceed the expected numbers in this series, which lends support to the validity of the statement that only one of these 46 deaths resulted from cord involvement. On the other hand, as was mentioned earlier, out of a total of fifteen death certificates of patients (not otherwise included in this study) who were known to have had rheumatoid cervical luxations with cord lesions, only two mentioned cord involvement as a contributory cause of death. This implies that cord damage may not always have been recognised as the cause of death and that cord involvement may have been responsible for more deaths than would appear from these figures.

The patients in this series were severely incapacitated and 70 per cent were in functional class 3 or 4 at the beginning of the study. Further evidence that

\section{(b) steroid treated patients}

Steroids

\begin{tabular}{|c|c|c|c|c|c|}
\hline Total & 2 & 7 & 20 & 1 & 39 \\
\hline 4 & & & & & 4 \\
\hline 3 & & & & & 13 \\
\hline \multirow[t]{2}{*}{2} & 2 & 6 & 1 & & 22 \\
\hline & 0 & 2 & 3 & & otal \\
\hline
\end{tabular}

Final grade

(b) steroid treated patients

Steroids

\begin{tabular}{|c|cccc|c|}
\hline Total & 14 & 19 & 8 & 1 & 42 \\
\hline 4 & & & & & \\
3 & 2 & 5 & 3 & & 10 \\
2 & 12 & 14 & 5 & 1 & 32 \\
0 & \multicolumn{1}{c}{$/$} & & & & \\
\hline & 0 & 2 & 3 & 4 & Total \\
\hline
\end{tabular}

Final grade 
cervical luxations occur in patients with severe rheumatoid arthritis is evinced by the high proportion taking steroids (74 per cent. at follow-up) and the infrequency of seronegative cases ( 8 per cent.). Applying the survival tables for rheumatoid patients with this degree of incapacity, it can be calculated that a 55-year-old female has a 42 per cent. chance of surviving to 65 , as compared with an 88 per cent. chance for a female in the general population. (A similar survival pattern is found in males of comparable age and disease.) These considerations clearly apply when cervical fusion for rheumatoid luxations is being considered, particularly as the graphs of survival (Figs $6 a$ and $b$ ) suggest that such lesions do not significantly shorten life.

In this series the incidence and severity of forward luxations at C.1/2 was unrelated to age or the duration of the rheumatoid disease. Downward luxation at C.1/2 was related to age and disease duration; only three out of nineteen patients were less than 60 years of age when this was diagnosed. During the course of the study ten patients developed downward luxation of C.1 on C.2. Of these three arose in previously normal C.1/2 articulations whilst seven evolved in patients who originally had a forward luxation. It thus appears that downward luxation is usually preceded by forward luxation at C.1/2.

Both the frequency and the severity of luxations below C.1 were directly proportional to the age and the duration of disease; it is therefore possible that cervical disc degeneration contributes to the development of luxations at these levels.

From the evidence provided by this study one cannot predict the outcome of individual luxations but some generalizations emerge. Below C.1, 46 out of the 55 luxations (84 per cent.) had remained unaltered, improved, or recovered completely at follow-up, and at C.1/2 the comparable proportion was 61 per cent. ( 40 out of 66 ) - that is assuming that the final development of a downward luxation signified a deterioration.

Of the 45 patients provided with collars, only 22 had neck pain and, of the fourteen patients who wore their collars 'regularly', six complained of pain in the neck. It thus appears that regular collar wearing is unacceptable to most patients irrespective of the presence of neck pain. Inadequate immobilization is presumably the reason why collars did not benefit the radiological progression of luxations in this study.

This study indicates that cervical displacements occurring in seronegative patients progress more favourably than their seropositive counterparts and suggests that at C.1/2 forward luxations progress less favourably in patients taking steroids.

\section{Conclusion}

A series of 130 patients with classical or definite rheumatoid arthritis who showed cervical luxations but no cord or brainstem involvement were reexamined 5 to 14 years after the luxations were first detected, and during this interval 52 died. During this time four patients developed cord involvement and six others symptoms suggestive of vertebral ischaemia.

There were initially 121 luxations amongst the 84 survivors, and at follow-up just over a quarter had increased, slightly less than a half had remained unaltered, and a quarter had either improved or recovered completely. A study of survival tables suggests that cervical luxations per se do not significantly shorten life in patients with rheumatoid arthritis. Luxations appeared to progress more favourably in patients with negative sheep cell agglutination tests. Collars, as prescribed in this series, had no demonstrable effect on the radiological progress of luxations, but steroid therapy appears to have an adverse effect on forward luxations at C.1/2.

We wish to thank Prof. J. H. Kellgren for allowing us to study his patients and for helpful advice in the preparation of this paper; also Miss P. Jeffries for taking domiciliary radiographs. Our thanks are due to Dr.P.H. N. Wood and his staff for their help in tracing patients; to Dr. P. L. Boardman, Dr. H. H. Corrigall, Dr. O. P. Galpin, and Dr. J. K. Lloyd Jones, who helped with individual cases; and also to the Department of Medical Illustration for technical assistance. In addition we would like to thank Dr. T. G. Reah for permitting us to use his data.

\section{References}

BaLl, J., and SharP, J. (1971) 'Rheumatoid arthritis of the cervical spine', in Modern Trends in Rheumatology 2', ed. A. G. S. Hill, 2nd. ed., p. 117. Butterworths, London

Conlon, P. W., ISDAle, I. C., and Rose, B. S. (1966) Ann. rheum. Dis., 25, 120 (Rheumatoid arthritis of the cervical spine)

Reah, T. G. (1963) Proc. roy. Soc. Med., 56, 813 (The prognosis of rheumatoid arthritis)

-, BENN, R. T., and Wood, P. H. N. (1971) 'Mortality in Rheumatoid Arthritis'. Abstracts of the Seventh European Rheumatology Congress, Brighton

Registrar General (1968). 'Decennial Supplement: England and Wales, 1961.' Life Tables. H.M.S.O., London

SharP, J. (1964) 'Cervical spine', in 'Radiological Aspects of Rheumatoid Arthritis', ed. M. E. Carter, p. 219 (International Congress Series No. 61). Excerpta Medica Foundation, Amsterdam and Purser, D. W. (1961) Ann. Rheum. Dis., 20, 47 (Spontaneous atlanto-axial dislocation) 